\title{
Investigate the Process Parameter on the Friction Stir Welding of Dissimilar Aluminium Alloys
}

\author{
R. Raja $\mathbb{D}^{1},{ }^{1}$ A. Parthiban $\left(\mathbb{D},{ }^{1}\right.$ S. Nandha Gopan $\mathbb{D}^{\circ},{ }^{2}$ and Derese Degefa ${ }^{3}{ }^{3}$ \\ ${ }^{1}$ Department of Mechanical Engineering, Vels Institute of Science, Technology \& Advanced Studies, Chennai, India \\ ${ }^{2}$ Department of Mechanical Engineering, K.Ramakrishnan College of Engineering, Trichy, India \\ ${ }^{3}$ Department of Mechanical Engineering, WOLLO University, Kombolcha Institute of Technology, Kombolcha, \\ Post Box No: 208, Ethiopia \\ Correspondence should be addressed to Derese Degefa; derese2013@kiot.edu.et
}

Received 9 September 2021; Accepted 4 December 2021; Published 22 January 2022

Academic Editor: Temel Varol

Copyright $\odot 2022$ R. Raja et al. This is an open access article distributed under the Creative Commons Attribution License, which permits unrestricted use, distribution, and reproduction in any medium, provided the original work is properly cited.

\begin{abstract}
The welding of different materials with an acceptable quality range is an emerging study area; engineers and scientists worldwide have long been concerned with dissimilar welding materials. This study focuses on determining the friction stir welding of different aluminuim alloys; an experimental investigation was conducted (AA7475-T651 and AA2219-O). It also describes the FSW process parameters and response measurement for defining weld quality and the procedure for measuring them. Taguchi L27, orthogonal array method, is preferred for optimizing FSW parameters such as shoulder diameter, tool rotational speed, and traverse speed. The effect of welding parameters is investigated through the ANOVA table and graphs. The SEM analysis investigates the fracture and micrographic analysis in the heat-affected zone and thermo-mechanically affected zone.
\end{abstract}

\section{Introduction}

Dissimilar welding materials are vital for various goods used in automotive, shipbuilding, aerospace, and other industries. This can be such a difficult task that it is sometimes impossible to acquire a joint. In particular, this difficulty is caused by variations in the mechanical characteristics of the connected components (physical, chemical, and metallurgical). Even during welding, there may be failures at the weldments because of differences in melting point and thermal expansion coefficient. Aluminium alloys are used for structural components because of their fracture toughness, good corrosion resistance, and fatigue strength. Aluminium alloys are lightweight materials that minimize vehicle bulk, therefore reducing fuel consumption and hazardous emissions. As lightweight materials, many aluminium alloys meet the needs of the aircraft sector [1]. AA7475 outperforms numerous commercially available high-strength aircraft aluminium alloys such as AA7075 and AA7050 [2]. For connecting 6 mm AA6351-T6 and AA5083-
H111, reseachers used HCHCr steel [3]. For connecting $8 \mathrm{~mm}$ different aluminium alloys, researchers employed H13 steel (AA7075-T6 and AA6082-T6) [4]. Khan et al. [5] utilised an HCHCr steel threaded pin tool to link $2.5 \mathrm{~mm}$ AA7475-T761 and AA2219-O.

There are some examples of aluminium alloys being joined, such as a ship's $5 \mathrm{xxx}$ aluminium alloy being joined to $6 \mathrm{xxx}$ aluminium and an aircraft's $2 \mathrm{xx}$ being joined to a $7 \mathrm{xxx}$ series aluminium alloy, due to extreme plastic deformation and low heat input [6]. This results in more minor prewelding processing benefits and increased joint strength. To create the sound welded connection, FSW employs heat generated by friction between the tool and base material (BM), which softens materials that form the joint and causes plastic deformation of the base material, as shown in Figure 1. Al-A2219 and Al-7475 are frequently used in aircraft. It follows that research on connecting such alloys might be of both scholarly and industrial use. Conventional fusion welding methods are unable to fuse the aerospace aluminium alloys AA2219 and AA7475 adequately. As a result, 


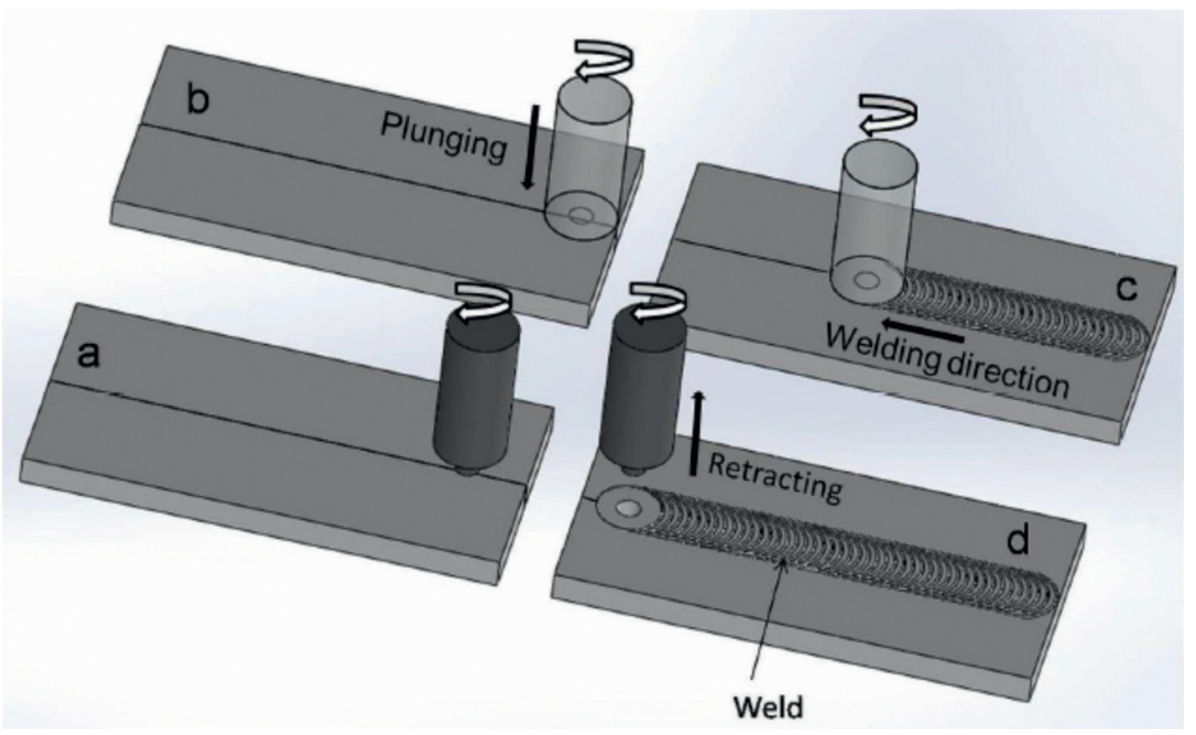

FIGURE 1: Steps of friction stir welding process.

joining such alloys requires the use of a different welding technique. Welding different aluminium alloys with FSW is a suitable option [7].

Three microstructural zones are visible in welded FS joints (Figure 2). Recrystallized grains appear in the stir zone (SZ). Plastically deformed grains appear in thermomechanically affected zone (TMAZ) [8]. Die Region SZ, in which dynamic recrystallization produced by the stirring action of the tool results in refined grains, is subjected to high deformation and high heat input. Plastic deformation occurs up to a lower level in the region next to SZ (TMAZ), which leads to partial dynamic recrystallization. The HAZ is exclusively subjected to a temperature influence [9].

\section{Material Selection}

This paper presents the methodology of dissimilar welding in aluminium alloys ( $2 \mathrm{xxx}$ and $7 \mathrm{xxx}$ ) with prospective applications in important areas [10]. AA2219-O with AA7475T761 (a combination usually utilised in aircraft construction) was FSW, and its microstructure and mechanical characteristics were studied and presented in this paper.

BMs used in the present research were hot rolled AA7475-T651 and AA2219-O plates of thickness $2.5 \mathrm{~mm}$. The plates were sheared to nominal dimensions of $50 \mathrm{~mm} \times 180 \mathrm{~mm}$ so that the grains aligned in the direction of the joint line. The experiments were performed on the plates in the rolling direction [11-13]. Figure 3 shows the geometric layout representation of HC steel for FSW. Table 1 lists the composition of BM alloys and the tool material HC steel. It is shown in Table 2 that BMs have mechanical and thermal characteristics.

In high-strength aluminium alloys, friction stir welding has shown to be a formidable welding method. An R. V. machine tools' limited friction stir welding machine was used for the tests (Figure 4). Two motors control the friction stir welding process: the spindle motor and feed motor. These motors are connected to driving controllers through a wire. Its spindle

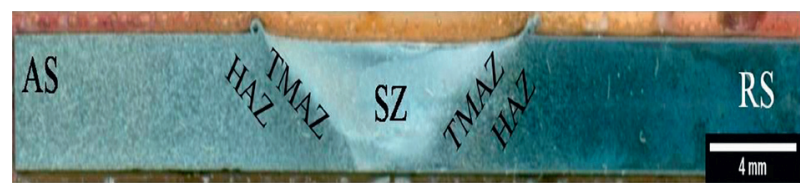

FIGURE 2: Microstructural welding zones of friction stir-welded aluminium alloy.
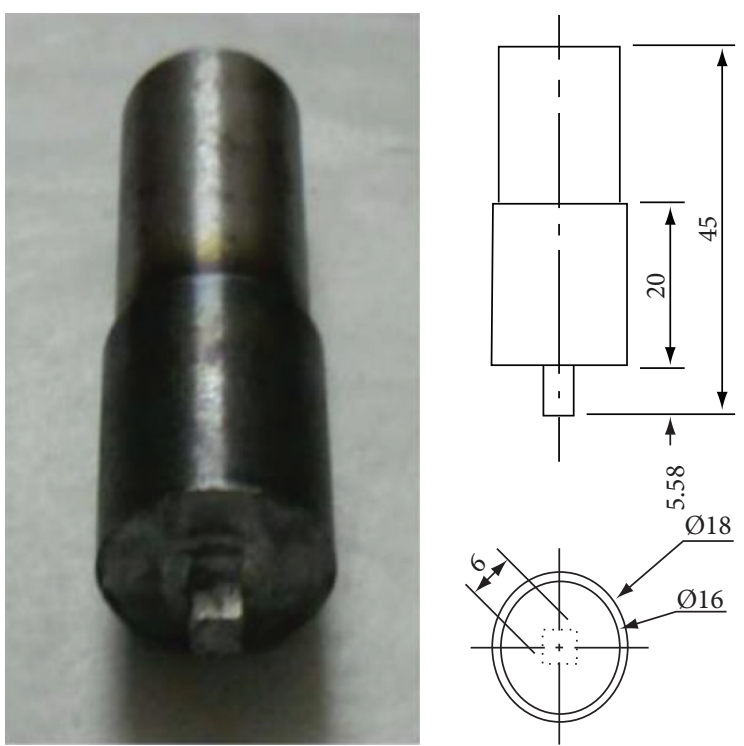

FIGURE 3: HC steel FSP tool and its geometric layout.

motor has a power rating of $22 \mathrm{~kW}$, while its feed bed motor has a power rating of $1.5 \mathrm{~kW}$. Motors with mechanical gearboxes are used in both cases to enhance torque at the output shaft. The spindle rotation is provided by a primary spindle motor, while the feed bed motor provides power for the bed's three-axis motions. With $24 \mathrm{~V}$ electromagnetic clutches, the different axes of the bed $(X, Y$, and $Z$ ) are locked into place. PCI boards are connected to limit switches and emergency stop 
TABle 1: AA7475, AA2219, and HC steel: chemical properties (wt. \%).

\begin{tabular}{lcccccccccccccc}
\hline Elements & $\mathrm{Al}$ & $\mathrm{Cu}$ & $\mathrm{Mg}$ & $\mathrm{Sn}$ & $\mathrm{Mn}$ & $\mathrm{Fe}$ & $\mathrm{Si}$ & $\mathrm{Ti}$ & $\mathrm{Cr}$ & $\mathrm{Zn}$ & $\mathrm{Ni}$ & $\mathrm{Zr}$ & $\mathrm{C}$ & $\mathrm{V}$ \\
\hline AA2219 & 91.96 & 6.91 & - & 0.016 & 0.32 & 0.101 & 0.06 & 0.02 & 0.17 & 5.38 & 0.002 & 0.007 & - & - \\
AA7475 & 90.99 & 1.34 & 1.93 & 0.016 & 0.32 & 0.156 & 0.044 & 0.06 & - & 0.06 & 0.034 & 0.293 & - & 0.147 \\
HC steel (tool) & - & 0.10 & - & - & 1.39 & 95.43 & 0.53 & - & 0.433 & - & 0.084 & - & 0.88 & - \\
\hline
\end{tabular}

TABLE 2: AA7475 and AA2219: mechanical and thermal characteristics.

\begin{tabular}{lccccc}
\hline Materials & UTS (MPa) & Yield strength (MPa) & Percentage of elongation (\%) & $\begin{array}{c}\text { Material thermal } \\
\text { conductivity (W/mK) }\end{array}$ & $\begin{array}{c}\text { Incipient melting liquids' } \\
\text { temperature }\left({ }^{\circ} \mathrm{C}\right)\end{array}$ \\
\hline AA7475-T651 & $460-470$ & $425-435$ & $12-15$ & $162-165$ & $535-635$ \\
AA 2219-O & $290-295$ & $215-230$ & $14-16$ & $115-125$ & $545-645$ \\
\hline
\end{tabular}

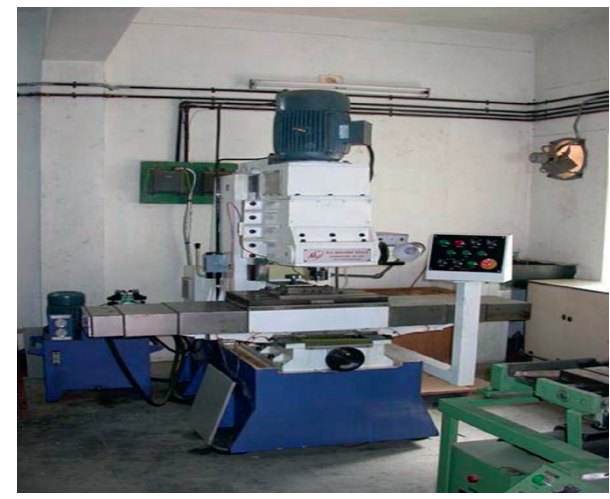

FIgURE 4: Friction stir welding.

buttons $[14,15]$. Figure 4 shows the fixture set up on the FSW machine. By securing the plates to be stir-welded, all degrees of freedom are prevented, resulting in high-quality welding.

\section{Taguchi Analysis}

Many trail experiments were performed at different parameter combinations by varying process parameters to determine the feasible range of the selected parameters. Table 3 shows the FSW process parameter window with the specified parameters' minimum and maximum values.

The experiment plan shows the number of experiments and the order in which each experiment is required to be conducted. Three process parameters are selected in the present research along with three levels of each parameter, and 27 experiments are performed according to Taguchi's L27 orthogonal array (OA) [16]. Taguchi's L9 OA can also be used with the selected factors and levels, but this design does not allow the experimenter to investigate the effects of the interaction of the process parameters on the response variables. In order to investigate the effect of main factors and their interactions on the response variables, Taguchi's L27 OA was selected to perform the experiments, as shown in Table 4 . The experimental plan based on Taguchi's L27 OA is presented with randomized order and date of experiment in Table 5.

3.1. Microstructural Investigation. In order to determine the location of internal flaws and defects, examine causes for poor strength, and comprehend the process of material
TABLE 3: FSW process parameter window.

\begin{tabular}{lccc}
\hline FSW process parameters & \multicolumn{3}{c}{ Levels } \\
& Level I & Level II & Level III \\
\hline $\begin{array}{l}\text { Parameter 1: rotational speed }(A) \\
\text { (rpm) }\end{array}$ & 710 & 900 & 1120 \\
$\begin{array}{l}\text { Parameter 2: traverse speed }(\mathrm{mm} / \\
\text { min) (B) }\end{array}$ & 160 & 200 & 250 \\
$\begin{array}{l}\text { Parameter 3: shoulder diameter (mm) } \\
(C)\end{array}$ & 10 & 12 & 14 \\
\hline
\end{tabular}

flow, friction stir-welded samples were subjected to microstructural analysis. Optical microscopy was used to analyze microconstituent and grain structures and morphology, and advanced examination was done using scanning electron microscopes (SEM) [17].

\section{Results and Discussion}

4.1. Traverse Force. Table 4 shows the experimentally measured traverse force data. Standard statistical software Minitab-17 was used to analyze experimental data. Traverse force was determined based on a "lower is better" (minimization) criterion because a lower value results in reduced tool wear (Figure 4), less load on the machine spindle and work fixture, etc. Table 4 shows the results of an analysis of the mean (ANOM) to identify the optimal parameter combination.

The impact of FSW parameters and their interplay on traverse force was assessed using ANOVA. Before executing an ANOVA, a diagnostic test is necessary to validate the assumptions stated in the ANOVA. The Minitab-17 program generated a normal probability plot (Figure 5). In Figure 5, it can be observed that the points (residuals) either lie on or are extremely close to the straight line. Thus, the residuals are normally distributed, and it validates the ANOVA assumption.

Figure 6 shows the normal probability plot for the values of traverse force. Furthermore, the results of ANOVA also indicate the significance of factors and their interactions defined in terms of percent contribution. Percent contribution gives the order of importance for each parameter and interaction affecting the traverse force in Table 6 . Shoulder diameter $(C)$ is identified as the most influencing factor because it directly affects the 
TABLE 4: Response table for mean (traverse force).

\begin{tabular}{lccccc}
\hline FSW parameters & Level 1 & Level 2 & Level 3 & Difference & Rank \\
\hline Parameter 1 & 71.09 & 57.60 & 56.34 & 14.74 & 3 \\
Parameter 1 & 49.43 & 62.06 & 73.54 & 24.11 & 2 \\
Parameter 1 & 53.33 & 50.89 & 80.81 & 29.92 & 1 \\
\hline
\end{tabular}

TABle 5: Taguchi L27 OA showing 27 experiments.

\begin{tabular}{lccc}
\hline Ex. no & \multicolumn{3}{c}{ Factors and their levels } \\
& Parameter 1 & Parameter 2 & Parameter 3 \\
\hline 1 & 1 & 1 & 1 \\
2 & 1 & 2 & 2 \\
3 & 1 & 3 & 3 \\
4 & 2 & 1 & 1 \\
5 & 2 & 2 & 2 \\
6 & 2 & 3 & 3 \\
7 & 3 & 2 & 1 \\
8 & 3 & 3 & 2 \\
9 & 3 & 1 & 3 \\
10 & 1 & 2 & 2 \\
11 & 1 & 3 & 3 \\
12 & 1 & 1 & 1 \\
13 & 2 & 2 & 2 \\
14 & 2 & 3 & 3 \\
15 & 2 & 1 & 2 \\
16 & 3 & 2 & 3 \\
17 & 3 & 3 & 1 \\
18 & 3 & 1 & 3 \\
19 & 1 & 2 & 1 \\
20 & 1 & 3 & 2 \\
21 & 1 & 1 & 3 \\
22 & 2 & 2 & 1 \\
23 & 2 & 3 & 2 \\
24 & 2 & 1 & 1 \\
25 & 3 & 2 & 2 \\
26 & 3 & & 3 \\
27 & 3 & 3 & 2 \\
\hline
\end{tabular}

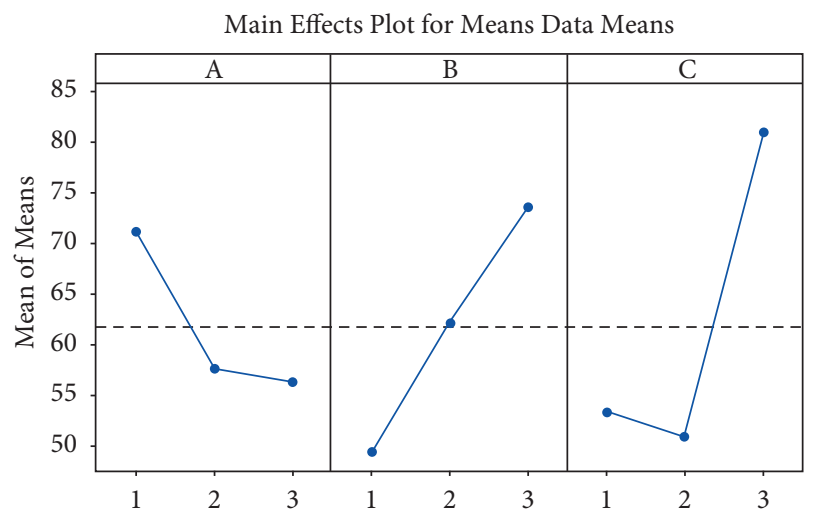

Figure 5: Main effect plot for the mean (traverse force).

traverse force with a higher percentage contribution of $32.45 \%$, followed by interaction $\mathrm{A} \times \mathrm{C}$ with $18.72 \%$ contribution, traverse speed $(B)$ with $17.22 \%$ contribution, interaction $A \times B$ with $13.82 \%$ contribution, interaction $B \times C$ with $7.13 \%$ contribution, and rotational speed with $6.90 \%$ contribution.

$$
\begin{aligned}
\text { Transverse Force }_{\text {avg }}= & 1-0.020 A+0.883 B-12.1 C \\
& -0.000990 A * B+0.0155 A * C \\
& +0.0237 B * C .
\end{aligned}
$$

Equation (1) gives the following formula for predicting the traverse force in terms of factors.

The coefficient of determination is derived by the combinations of welding parameters and traverse force, i.e., $R 2$. For the relationship shown in equation (1), a very high value of $R 2=96.2 \%$ is obtained, which indicates that $96.2 \%$ variation in the value of traverse force is explained by variation in the values of the FSW parameters and only a very small $(3.8 \%)$ variation in the value of traverse force is not explained by variation in the values of the FSW parameters.

4.2. Effect of Rotational Speed on Traverse Force. Factor A variations affect traverse force, as seen in Figure 7 (i.e., rotational speed). When shown in Figure 7 , the traverse force decreases sharply as the rotational speed increases from level 1 to 2 . On the contrary, the traverse force decreases significantly less with an increase in rotational speed from level 2 to level 3.

This is because friction heat and strain rate are increased when rotational speed increases. An increase in frictional heat reduces the traverse force, while the increase in strain rate causes an increase in traverse force. An increase in rotational speed might significantly enhance the frictional heat compared to the strain rate. Thus, the effect of frictional heat takes over the effect of strain rate on traverse force, thereby reducing traverse force.

4.3. Effect of Traverse Speed on Traverse Force. Figure 8 shows the influence of traverse speed, or factor $B$, on traverse force. Level II traverse speed results in greater forces. When traverse speed is increased from level II to level III, the traverse force increases again. During welding, the traverse speed has a major impact on the distribution of the heat generated. Weld zone temperature rises with slower traverse speed, reducing flow stress. Higher traverse speed causes high flow stresses which increase the traverse force. Higher traverse speed increases the strain rate and decreases the weld temperature. Increased flow stress and increased traversal force are both enhanced by higher strain and lower temperature.

4.4. Effect of Shoulder Diameter on Traverse Force. The traversing force is reduced when the flow stress is low. However, an increase in shoulder diameter will result in more material being pushed under the shoulder, reducing tool travel and resulting in a greater force. As a result, when frictional heat is dominant, the shoulder diameter is increased the traverse force is reduced. When the moving material's resisting force is dominant, the shoulder diameter increases and the traverse force also increases (Figure 9). This may be expected that the effect of resisting force applied 
TABle 6: The ANOVA table for traverse force.

\begin{tabular}{|c|c|c|c|c|c|c|}
\hline Source & Sum of squares & $\mathrm{DF}$ & Mean square & $F$ value & Prob $>F$ & $\%$ contribution \\
\hline $\bar{A}$ & 20.14 & 2 & 10.07 & 7.35 & 0.015 & 6.90 \\
\hline$B$ & 50.20 & 2 & 25.10 & 18.31 & 0.001 & 17.22 \\
\hline C & 94.59 & 2 & 47.29 & 34.50 & 0.000 & 32.45 \\
\hline$A \times B$ & 40.28 & 4 & 10.07 & 7.35 & 0.009 & 13.82 \\
\hline$A \times C$ & 54.56 & 4 & 13.64 & 9.95 & 0.003 & 18.72 \\
\hline$B \times C$ & 20.78 & 4 & 5.19 & 3.79 & 0.052 & 7.13 \\
\hline Residual & 10.97 & 8 & 1.37 & & & 3.76 \\
\hline Total & 291.51 & 26 & & & & \\
\hline
\end{tabular}

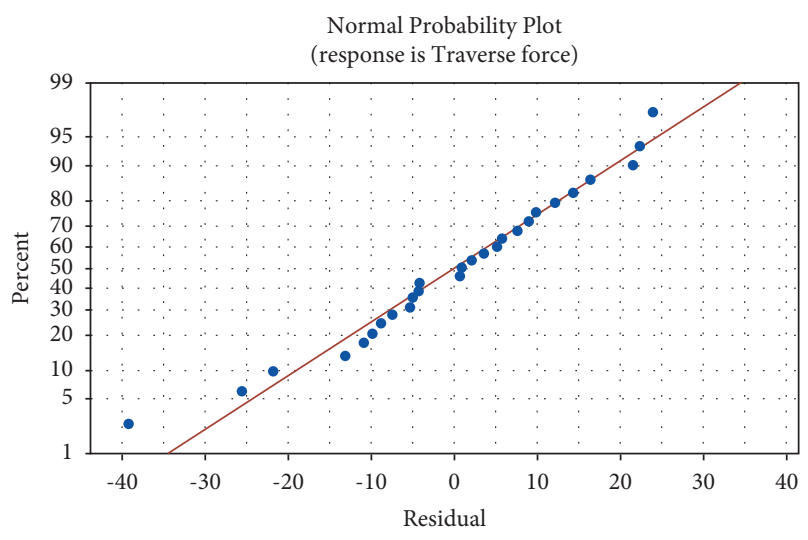

FIGURE 6: Normal probability plot for the values of traverse force.

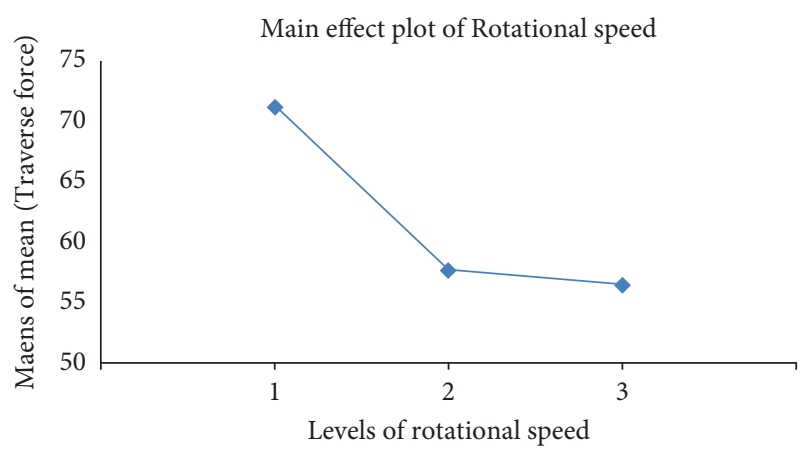

Figure 7: Main effect plot of rotational speed for means (traverse force).

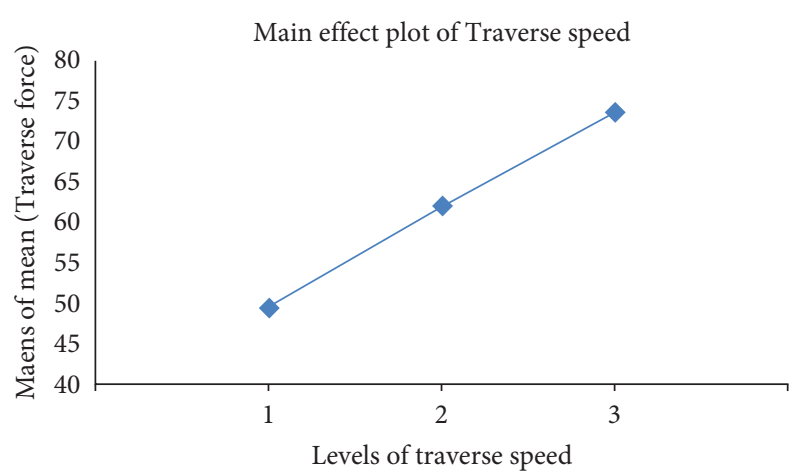

FIGURE 8: Main effect plot of traverse speed for means (traverse force).

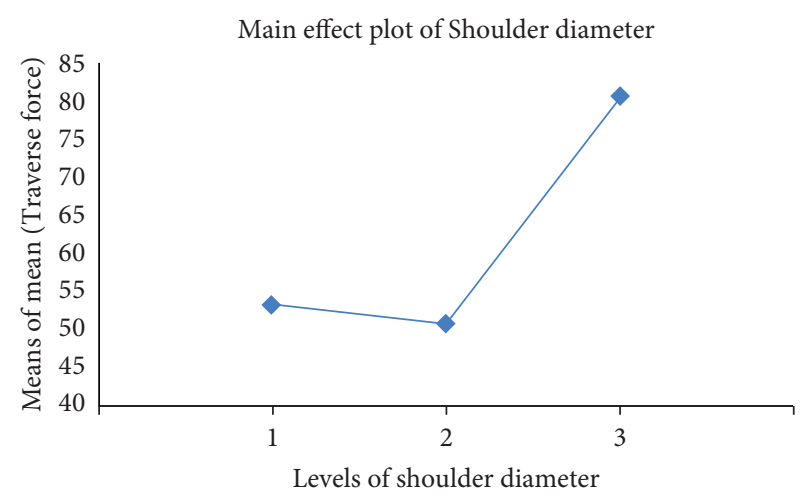

FIGURE 9: Main effect plot of shoulder diameter for means (traverse force).

by the moving material under the tool shoulder dominates over the effect of frictional heat and the effect is an increase in the traverse force on increasing shoulder diameter. Figure 10 denotes the interaction between rotational speed and traverse speed $(A \times B)$ on average traverse force, and Figure 11 represents the interaction between rotational speed and shoulder diameter $(A \times C)$ on average traverse force.

4.5. SEM Analysis. Figure 12 shows very few precipitates at $\mathrm{RS}$, whereas a high density of precipitates is observed at AS of SZ. It might be due to sufficient temperature generated at SZ and dissolved strengthening precipitates at RS. While AS material was used in annealed conditions, and precipitates shown in $\mathrm{SZ}$ might be undissolvable $\mathrm{Al}_{2} \mathrm{Cu}$ precipitates due to the presence of higher content of $\mathrm{Cu}$ in the $\mathrm{Al}$ matrix.

To achieve the desired shape and microstructure, the FSW process uses strain and heat. During FSW, many phenomena such as recovery, recrystallization, and grain growth occur depending on the kind of material, operating temperature, and degree of deformation. In FS welded materials, dynamic recovery and recrystallization occur, and these processes are responsible for grain refinement. The strain rate and available temperature dictate the degree of grain refining. With a higher strain rate and a lower temperature, grain size shrinks. FSW variables such as tool rotation speed, traverse speed, and tool shoulder diameter affect temperature and strain rate. Although tool rotational speed, traverse speed, and shoulder diameter are all linearly connected, temperature in the weld zone rises as tool rotational speed rises but declines as traverse speed grows. Increased shoulder diameter enhances the tool's heat- 


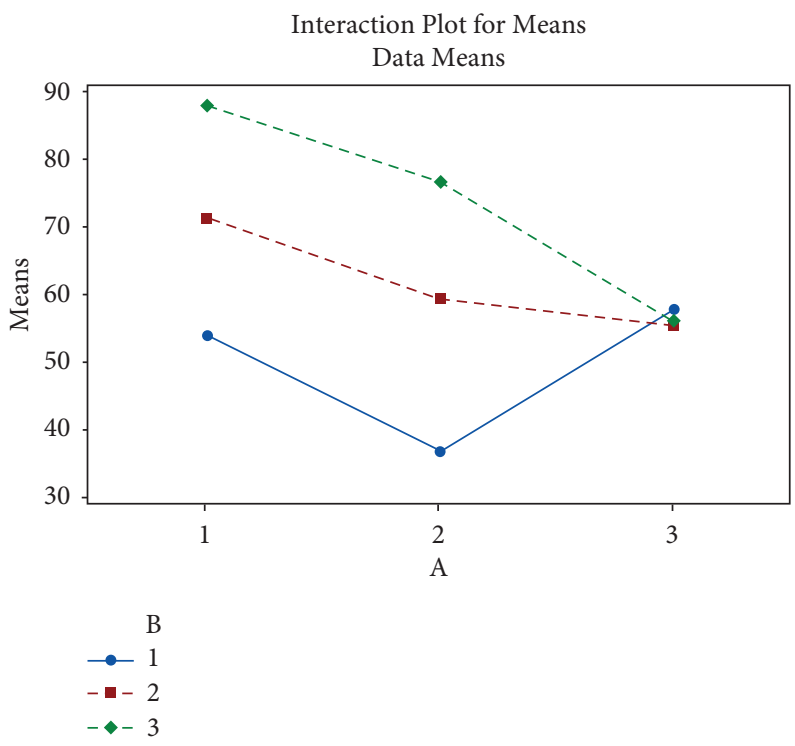

FIGURE 10: Effect of interaction between rotational speed and traverse speed $(A \times B)$ on average traverse force.

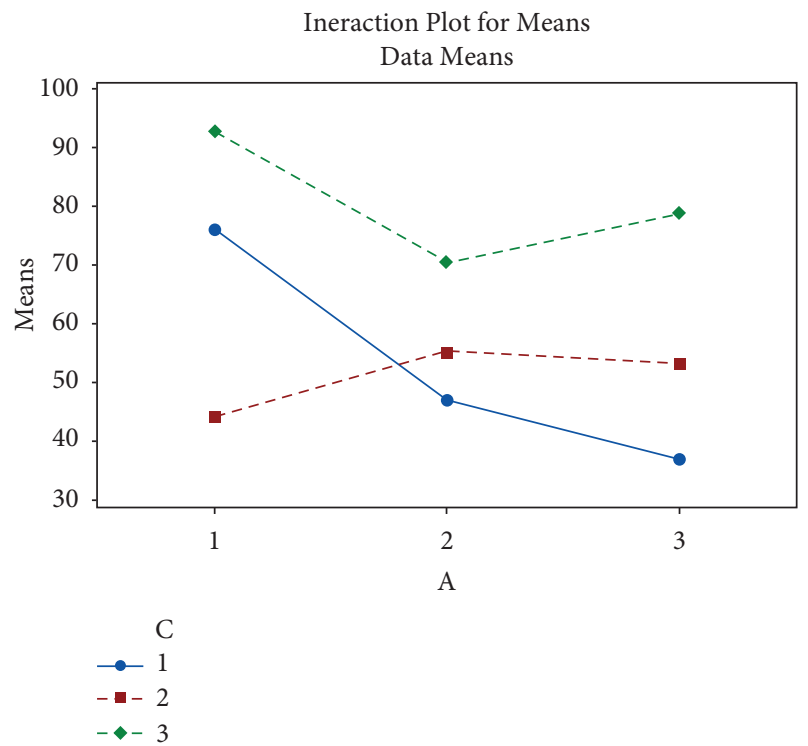

Figure 11: Effect of interaction between rotational speed and shoulder diameter $(A \times C)$ on average traverse force.

carrying capability while also increasing frictional heat. As a result, the impact of shoulder diameter on temperature is influenced by the interactions of other factors. Increased traversal speed raises the strain rate and lowers the temperature in the SZ, resulting in fine grain structure. After enduring intense plastic deformation and reaching higher temperatures, SZ may suffer dynamic recovery and dynamic recrystallization.

The grain structure of TMAZ is different depending upon the process parameter combination. Dark regions were found to be present at AS of the weld, as shown in Figure 13.

When examining broken specimens under a microscope, a variety of dimple characteristics can be seen. Some joints include a combination of shallow and deep dimples that are

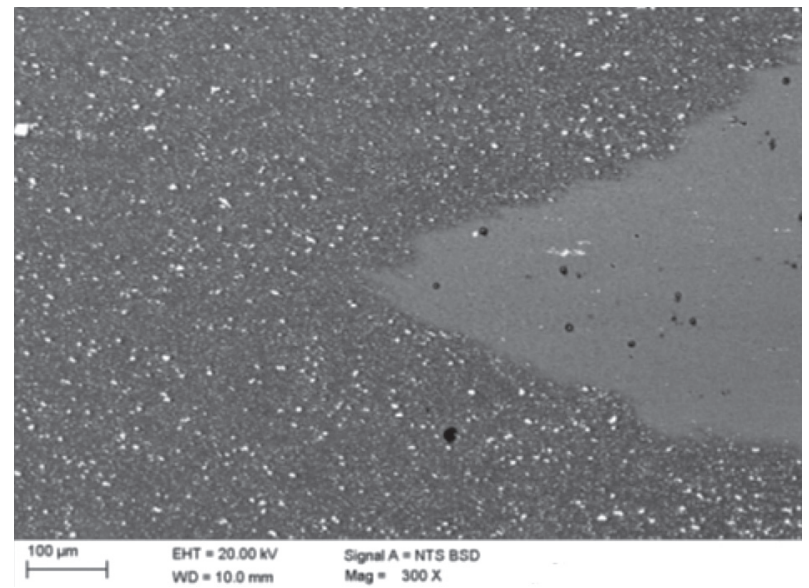

FIGURE 12: Micrograph for experiment no. 12 at SZ interface (RS on the right-hand side).

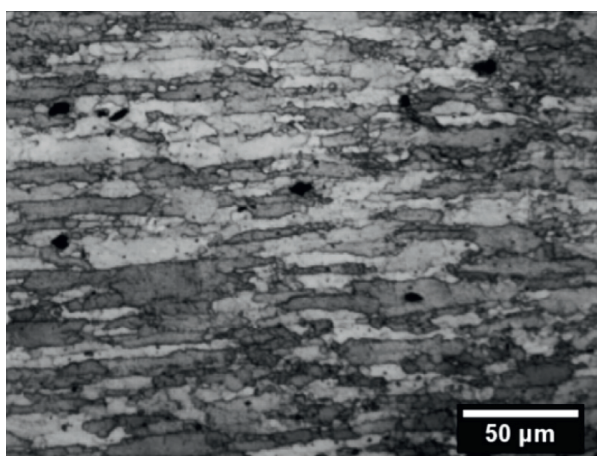

FIgURE 13: Micrograph of TMAZ in AS of the weld showing $\mathrm{Cu}$ rich dark regions.

less densely packed, as seen in Figure 14. Here, large, deep dimples formed due to void development, indicating that more energy was used before fracture. We find deep dimples 


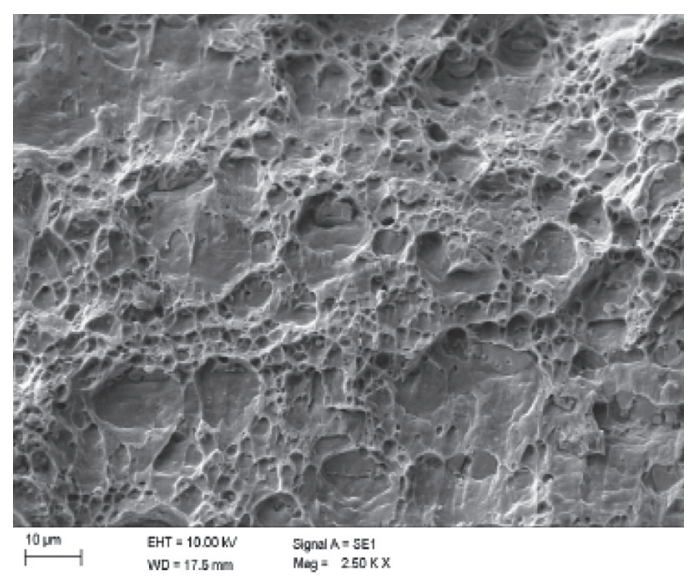

(a)

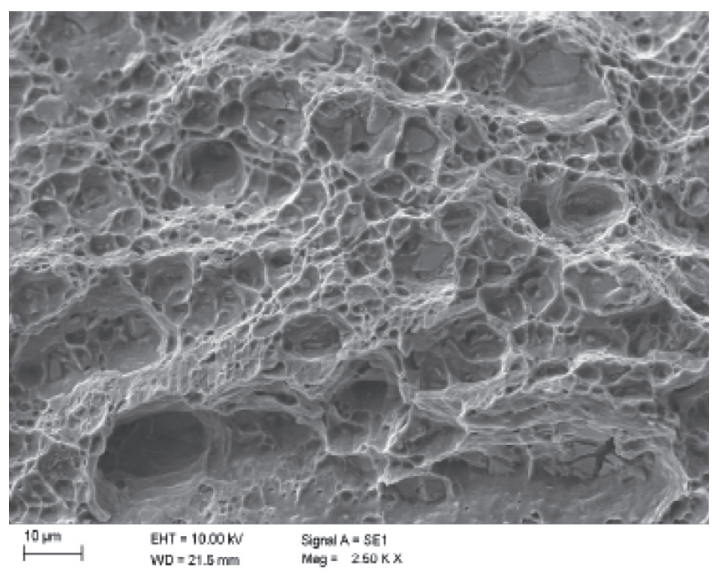

(b)

Figure 14: SEM micrograph of fractured specimen for exp nos. (a) 4 and (b) 17.

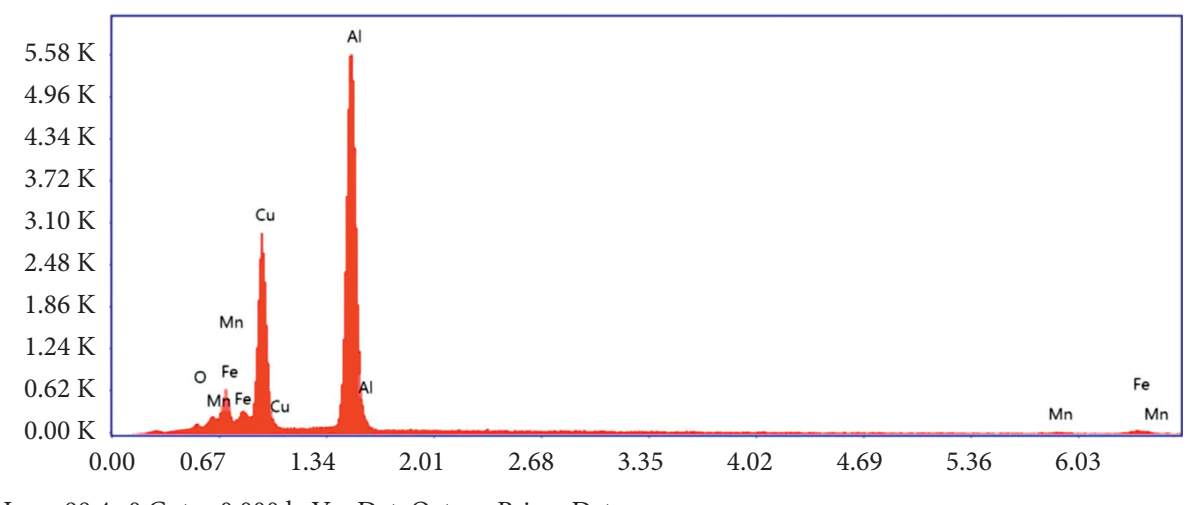

Lsec: 98.40 Cnts $0.000 \mathrm{keV}$ Det: Octane Prime Det

FIGURE 15: EDS spectrum of fractured specimen for exp no. 2.

that are densely populated, consistent with a typical ductile form of fracture.

The joint was fractured at the TMAZ is shown in Figure 14. The shallow dimples in the fractured sample are evidence of AS caused by cracking of the coagulated $\mathrm{Al} 2 \mathrm{Cu}$ precipitates. Figure 15 shows the EDS of the fractured sample for exp. no. 2, showing the presence of $\mathrm{Al}_{2} \mathrm{Cu}$ precipitates. Fe content in the EDS analysis might be due to fine Fe-rich precipitates present under the coagulated bigger $\mathrm{Al}_{2} \mathrm{Cu}$ precipitates.

\section{Conclusion}

The weld joint quality and traverse force measurements were used to determine the efficacy of the proposed work fixture. Conclusions derived from many experiments done on dissimilar aluminium alloys include

(1) An FSW tool with a threaded cylindrical pin made of high-carbon steel can be used to manufacture joints free of defects and to obtain good mechanical and metallurgical weld on aluminium alloys.
(2) After a high initial rise in traversal force, the curve drops to a lower value and stabilizes. Continued tool movement generates a steady increase in the curve, stabilizing at a higher traverse force value after some distance.

(3) After experiencing a sharp increase in traverse force, the curve lowers to a lower value and stabilizes. Continued tool movement generates a steady increase in the curve, stabilizing at a higher traverse force value after some distance.

(4) For the smallest traverse force, the optimal combination of the FSW parameters is $\mathrm{A} 3 \mathrm{~B} 1 \mathrm{Cl}$, which corresponds to the rotating speed of $1120 \mathrm{rpm}$, the travel speed of $160 \mathrm{~mm} / \mathrm{min}$, and shoulder diameter (C) of $10 \mathrm{~mm}$.

(5) Shoulder diameter $C$ (with 32.45 percent contribution), interaction $A \times C$ (with 18.72 percent contribution), traverse speed $B$ (with 17.22 percent contribution), interaction $A \times B$ (with 13.82 percent contribution), interaction $B \times C$ (with 7.13 percent contribution), and rotational speed $B$ (with 7.13 
percent contribution) are the factors and their interactions in order of importance for traverse force (with 6.90 percent contribution).

(6) On investigation of the microstructure, grain refinement occurs in the stir and thermo-mechanically affected zones due to the dynamic recrystallization. The process parameters' effect is shown on the size of recrystallized grains. In SZ, partial dissolution occurs and reprecipitations occur in some welds.

\section{Data Availability}

No data were used to support the findings of the study.

\section{Conflicts of Interest}

The authors declare that they have no conflicts of interest.

\section{References}

[1] P. P. Raja and B. J. Raj, "Investigations on mechanical and metallurgical properties of friction welding of AlB2 reinforced aluminum matrix composites," Silicon, vol. 10 , no. 4, pp. 1385-1391, 2018.

[2] R. K. Bhushan and D. Sharma, "Optimization of friction stir welding parameters to maximize hardness of AA6082/Si $3 \mathrm{~N} 4$ and AA6082/SiC composites joints," Silicon, vol. 12, pp. 1-19, 2021.

[3] N. Gangil, A. N. Siddiquee, and S. Maheshwari, "Investigation on the in-process traverse force evolution during surface composites fabrication on $\mathrm{Al}-\mathrm{Zn}-\mathrm{Mg}-\mathrm{Cu}$ alloy through friction stir processing," Materials Today Proceedings, vol. 25, pp. 686-690, 2020.

[4] M. Muthu Krishnan, J. Maniraj, R. Deepak, and K. Anganan, "Prediction of optimum welding parameters for FSW of aluminium alloys AA6063 and A319 using RSM and ANN," Materials Today Proceedings, vol. 5, no. 1, pp. 716-723, 2018.

[5] N. Z. Khan, A. N. Siddiquee, Z. A. Khan, and A. K. Mukhopadhyay, "Mechanical and microstructural behavior of friction stir welded similar and dissimilar sheets of AA2219 and AA7475 aluminium alloys," Journal of Alloys and Compounds, vol. 695, pp. 2902-2908, 2017.

[6] A. Sharma, V. K. Dwivedi, and Y. P. Singh, "Effect on ultimate tensile strength on varying rotational speed, plunge depth and welding speed during friction stir welding process of aluminium alloy AA7075," Materials Today Proceedings, vol. 26, pp. 2055-2057, 2020.

[7] P. Goel, A. K. Saxena, M. A. Wahid, S. Rathore, N. Sharma, and R. Kant Mishra, "Influence of friction stir welding parameters on mechanical properties of dissimilar AA 7475 to AISI 304," IOP Conference Series: Materials Science and Engineering, vol. 802, no. 1, Article ID 012010, 2020.

[8] R. Anand and V. G. Sridhar, "Effects of $\mathrm{SiC}$ and $\mathrm{Al}_{2} \mathrm{O}_{3}$ reinforcement of varied volume fractions on mechanical and micro structure properties of interlock FSW dissimilar joints AA7075-T6-AA7475-T7," Silicon, vol. 13, pp. 1-13, 2020.

[9] A. N. Siddiquee, S. Pandey, M. H. Abidi, A. Al-Ahmari, N. Z. Khan, and N. Gangil, "Microstructural characterization and in-process traverse force during friction stir welding of austenitic stainless steel," Proceedings of the Institution of Mechanical Engineers-Part C: Journal of Mechanical Engineering Science, vol. 234, no. 5, pp. 1031-1043, 2020.
[10] A. Haiter Lenin, S. C. Vettivel, T. Raja, L. Belay, and S. C. E. Singh, "A statistical prediction on wear and friction behavior of $\mathrm{ZrC}$ nano particles reinforced with $\mathrm{Al} \mathrm{Si} \mathrm{com-}$ posites using full factorial design," Surfaces and Interfaces, vol. 10, pp. 149-161, 2018.

[11] N. Z. Khan, A. N. Siddiquee, Z. A. Khan, D. Bajaj, and M. Ubaid, "Understanding the dissimilar friction stir welding through force and temperature evolution," Materials Today Proceedings, vol. 5, no. 9, pp. 17125-17131, 2018.

[12] O. Badran, N. Al-Kloub, A. M. Hassan, J. A. Al-Jarrah, and S. K. Khrais, "Effect of friction stir welding processing parameters on Abrasion wear Resistance of AA5083 welded joints," Material Science Research India, vol. 8, 2018.

[13] S. Pattnaik, P. K. Jha, and D. B. Karunakar, "A novel method of increasing ceramic shell permeability and optimizing casting shrinkage and tensile strength of the investment cast parts," Proceedings of the Institution of Mechanical EngineersPart B: Journal of Engineering Manufacture, vol. 231, no. 3, pp. 377-388, 2017.

[14] M. Srivastava and S. Rathee, "A study on the effect of incorporation of $\mathrm{SiC}$ particles during friction stir welding of $\mathrm{Al}$ 5059 alloy," Silicon, vol. 13, pp. 1-11, 2020.

[15] R. K. Bhushan and D. Sharma, "Optimization of parameters for maximum tensile strength of friction stir welded AA6082/ Si $3 \mathrm{~N} 4$ and AA6082/SiC composite joints," Silicon, vol. 12, pp. 1-15, 2019.

[16] A. Goyal and R. K. Garg, "Establishing mathematical relationships to study tensile behavior of friction stir welded AA5086-H32 aluminium alloy joints," Silicon, vol. 11, no. 1, pp. 51-65, 2019.

[17] C. Kalangi, V. Bolleddu, and H. Lenin Allasi, "Tribological characteristics of carbon nanotubes-reinforced plasmasprayed $\mathrm{Al}_{2} \mathrm{O}_{3}-\mathrm{TiO}_{2}$ ceramic coatings," Advances in Materials Science and Engineering, vol. 2021, Article ID 8094640, 2021. 